\title{
Assessing the Environment for Introduction of Human Papillomavirus Vaccine in India
}

\author{
Martha Jacob ${ }^{1, \#, *}$, Nita Mawar,", Lysander Menezes ${ }^{1}$, Satish Kaipilyawar ${ }^{1}$, Sanjay Gandhi ${ }^{1}$, Irfan \\ Khan $^{1}$, Manoj Patki ${ }^{1}$, Allison Bingham ${ }^{1}$, D. Scott LaMontagne ${ }^{1}$, Rajani Bagul ${ }^{2}$, Tuman Katendra ${ }^{2}$, \\ Neelima Karandikar ${ }^{2}$, Varada Madge ${ }^{2}$, Kishore Chaudhry ${ }^{3}$, Ramesh Paranjape ${ }^{2}$ and Anjali Nayyar ${ }^{1}$ \\ ${ }^{1}$ PATH, Seattle, WA, USA \& New Delhi, India \\ ${ }^{2}$ National AIDS Research Institute, Bhosari, Pune, India \\ ${ }^{3}$ Indian Council of Medical Research, New Delhi, India
}

\begin{abstract}
This paper presents findings from a study conducted in 2007 and 2008 in two states in India: Andhra Pradesh and Gujarat. The objectives of the study were to: (i) design effective and appropriate HPV vaccine delivery systems for 10- to 14-year-old girls; (ii) design a communication strategy for HPV vaccine delivery; and (iii) devise an HPV vaccine advocacy strategy.

The study populations included girls, parents, and local-, district-, and national-level stakeholders. A mixture of group discussions, visual representation techniques, face-to-face interviews, desk and health facility record reviews, field observations, and consultative workshops were used to collect the data.

Study findings showed that the policymakers, health care providers, parents, and adolescents were aware and concerned about cervical cancer; would welcome vaccination if safe, effective, affordable, and accessible. Health systems did not require large infrastructure investments to introduce HPV vaccine; basic cold chain and logistic equipment were available. New outreach systems for adolescent girls need to be tested through demonstration projects. No policies would compromise the introduction of HPV vaccination.

An HPV vaccine program, requiring public education and provider training, could be delivered. Policymakers' safety and vaccine efficacy concerns can be addressed through targeted advocacy efforts. Three broad approaches were suggested: (i) merge HPV vaccination with already established immunization services; (ii) package HPV immunization with adolescent health services or as a part of a cancer control service; and (iii) deliver HPV vaccinations through either routine immunization services or a campaign using schools as sites for school-going girls and anganwadi or village health centers for non-school-going girls.
\end{abstract}

Keywords: Cancer-cervix-formative study-HPV vaccines-immunization-screening.

\section{INTRODUCTION}

With one billion people, India has one-sixth of the world's population; it also carries one-fourth of the world's burden of cervical cancer [1-3]. If nothing is done, it is projected that these cancer figures will double by 2020 [1]. Human papillomavirus (HPV) is the primary cause of cervical cancer, with certain genotypes being more oncogenic. Of over 100 HPV genotypes, HPV 16 and HPV 18 are associated with some 70 percent of cervical cancer cases, both globally and in Asia, including India [4,5]. New screening and treatment approaches have been demonstrated to be effective [6-9], but making these approaches widely available remains a challenge. Effective HPV vaccine programs, along with continued strengthening of simple, evidence-based

*Address correspondence to this author at the HPV Vaccines: Evidence for Impact project, PATH, A-9 Qutab Institutional Area, New Delhi, India; Tel: 91112653 0080-88; Fax: 91112653 0089; E-mail: mjacob@path.org

"Dr. Martha Jacob and Dr. Nita Mawar contributed equally to the Formative Study. screening and treatment approaches, could significantly reduce the burden of cervical cancer.

Two commercially available vaccines have been shown to be effective against HPV genotypes 16 and 18. This has brought new hope for the prevention of cervical cancer. The two World Health Organization prequalified vaccines are Gardasil $^{\circledR}$, developed by Merck, and Cervarix ${ }^{\mathrm{TM}}$, from GlaxoSmithKline. Gardasil ${ }^{\circledR}$ is a quadrivalent vaccine that helps protect against four HPV types-the two most common oncogenic or high-risk HPV types, 16 and 18, and two common low-risk types that cause 90 percent of genital warts. Cervarix ${ }^{\mathrm{TM}}$ is a bivalent vaccine that protects against HPV 16 and 18. Both vaccines have to be provided as intramuscular injections in a three-dose schedule over six months. They have been shown to be well-tolerated and not only highly immunogenic but, most importantly, to provide protection against persistent infection and low- and highgrade precancerous lesions [10]. 
The National AIDS Research Institute (NARI), based in Pune, and PATH jointly conducted a formative study of HPV vaccine introduction in the Indian states of Andhra Pradesh and Gujarat. This formative study was part of the five-year global project, HPV Vaccines: Evidence for Impact. In India, this is a collaborative endeavor with the Indian Council of Medical Research (ICMR), Department of Health Research, Ministry of Health and Family Welfare, Government of India, and the state governments of Andhra Pradesh and Gujarat ${ }^{1}$. The next phase in the India endeavor would be a demonstration project.

This study investigated the sociocultural milieu, health system structures, and policy environments related to cervical cancer and HPV vaccines to generate information for the following three primary objectives relevant to government decision-making for potential future vaccine introduction:

(i) Designing effective and appropriate HPV vaccine delivery systems for 10- to 14-year-old girls;

(ii) Designing a communications strategy for HPV vaccine delivery;

(iii) Devising an HPV vaccine advocacy strategy.

\section{METHODS}

\section{Ecological Conceptual Framework Driven Study Approach}

The formative study was designed as a descriptive study based on an interdisciplinary, team-based, and qualitative research approach [11]. Guided by an ecological conceptual framework [12], the study analyzed five levels of influence for health-related behaviors: individual, interpersonal (household/local authority influencers), community/civil society, institutional, and public policy. The ecological approach recognizes that individual health behaviors are influenced at different levels within a complex environment (Fig. 1). A modified social ecology approach views health as a function of individuals and the environment in which they are embedded, including the family, social networks, communities, civil society organizations, institutions, and society as a whole [13].

\section{Study Populations and Sites}

The study populations were selected to represent the five levels-individual, interpersonal, community/civil society, institutional, and public policy-believed to influence effective vaccine introduction in the country (Table 1) [14]. The respondents for the sociocultural component included adolescent girls (school-going and out-of-school), parents, teachers, community leaders, health workers, and health authorities. For the health system review, we interviewed national and state policy players and consulted immunization experts. The policy review included national policymakers,

\footnotetext{
${ }^{1}$ Details about the planning and implementation of the HPV project in India are in the following unpublished manuscript available from PATH: Menezes, L.; Jacob, M.; Gandhi, S.; Kaipilyawar, S.; Patki, M.; Bingham, A.; Wittet, S.; LaMontagne, D.S.; Mawar, N.; Paranjape, R.; Chaudry, K.; Tsu, V. Developing an evidence base for cervical cancer vaccine introduction, planning and implementation in India. [Unpublished manuscript]. Available from PATH: Seattle, WA.
}

officials from key government ministries, leaders of medical and health professional associations, representatives of nongovernmental organizations (NGOs), and women's health advocates.

Why were the states of Andhra Pradesh and Gujarat selected? There were several compelling factors, including the level of cervical cancer disease burden, the fact that full immunization coverage was similar to national data [15], and that there was a degree of experience with new vaccine introduction such as the introduction of hepatitis B vaccine, as well as commitment to adolescent health and cervical cancer prevention. There was also expressed willingness to participate in the project.

Specific additional criteria were used to select the study districts of Khammam and Vadodara: the percentage of married girls less than 18 years old [15, 16], percentage of children aged 12 to 35 months who had received full vaccination, percentage of women visited by auxiliary nurse midwives (ANMs) or health workers, literacy rate [17], and percentage of school drop-out in grades 1-5 [18]. In each district, three study blocks (administrative units) were identified based on distribution of urban, rural, and tribal populations.

\section{Data Collection and Sources}

The following methods were used for the sociocultural component: group discussions (or focus group discussions), visualization methods such as daily activity charts, immunization flow diagrams, well-being spider diagrams, and cervical cancer discussions. For the health systems review, desk reviews, immunization experts' consultation, exit interviews with mothers, and observations of vaccine services were carried out. Face-to-face interviews (or in-depth interviews) with key respondents in their workplaces were conducted for the policy review. Different data collection methodologies were used for different study groups, each of which offered a perspective on the same study component (Table 2).

The study design was iterative, where data collection was adjusted according to what was learned about current awareness and perceptions of the community, health service providers, and policymakers. Purposive sampling was used to allow the study to focus on people who would be most likely to experience, know about, and have insights into the range of research topics included in the study. The study aimed to elicit credible opinions; the selected group of community members, service providers, and policymakers comprised finite, well-defined, and known population groups in specified settings reflecting diversity in perspectives.

Themes relevant for data collection of the sociocultural milieu were the concept of health and health-seeking behavior among adolescent girls; decision-makers and influencers of adolescent girls' health needs; understanding and perception of cancer, cervical cancer and its implications; experiences with vaccination, HPV vaccine, and its introduction; and possible communication messages and methods (Table 3).

To understand the health system, we explored the following themes: system readiness, effect of introduction on 


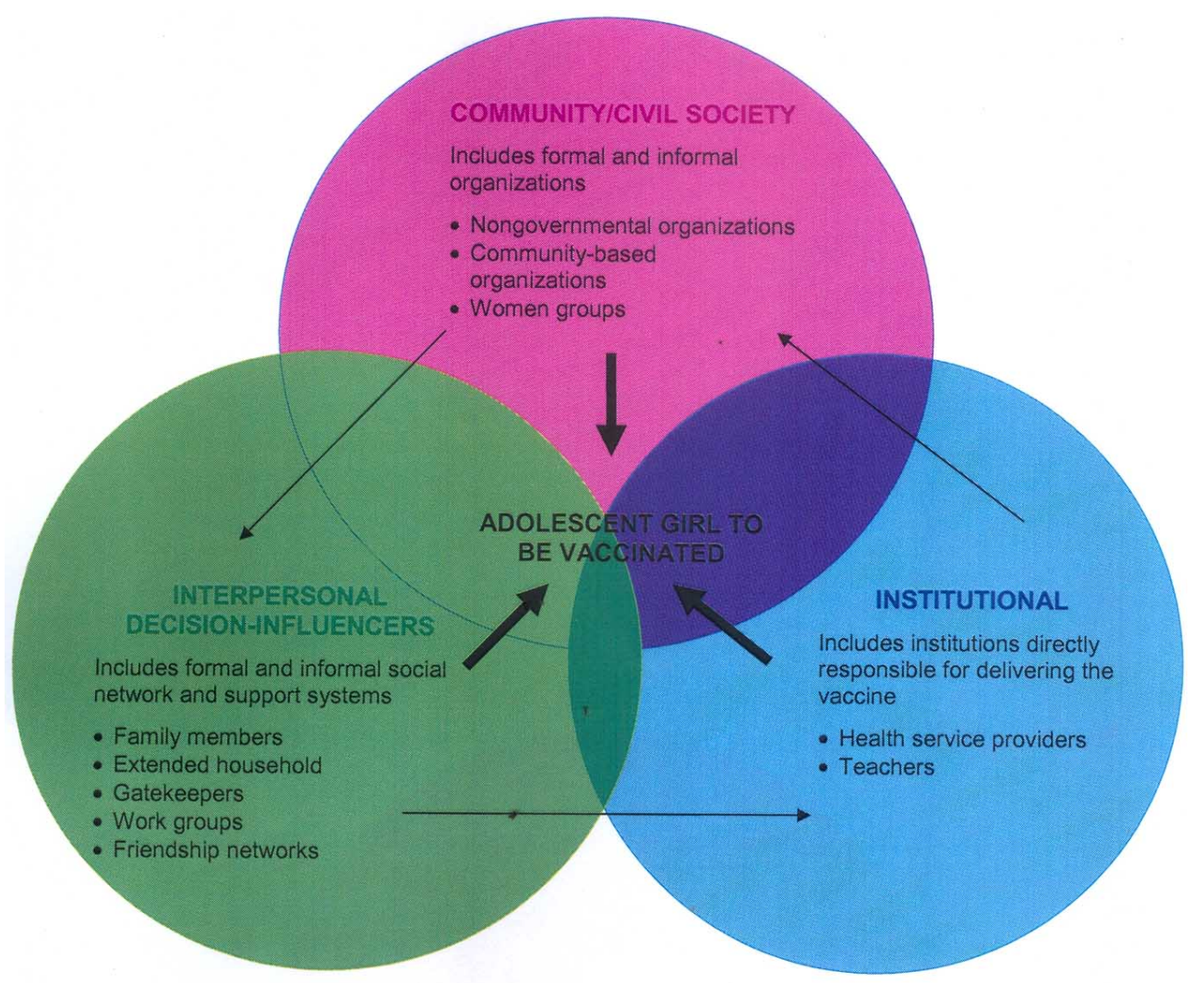

Fig. (1). Ecological framework and levels of influence for HPV vaccination in India.

Table 1. Sampling Design by Ecological Levels

\begin{tabular}{|c|c|}
\hline Levels & Data Collection and Sampling by Study Populations \\
\hline \multicolumn{2}{|l|}{ Individual } \\
\hline Study population & 10- to 14-year-old girls (in- and out-of-school) \\
\hline Data collection & FGD, IDI \\
\hline Sampling & Purposive for FGD and IDI \\
\hline \multicolumn{2}{|l|}{ Interpersonal } \\
\hline Data collection & FGD, IDI \\
\hline Sampling & Purposive for FGD and IDI \\
\hline \multicolumn{2}{|c|}{ Community/Civil Society } \\
\hline Study population & Community leaders; NGOs; elected ward and village leaders; religious leaders; local leaders \\
\hline Study population & $\begin{array}{l}\text { Education and health personnel (local, state, national), teachers, headmasters, health workers including community } \\
\text { health workers, immunization experts (state \& national) }\end{array}$ \\
\hline Data collection & FGD, IDI, expert consultation \\
\hline Sampling & Purposive for FGD, IDI, expert consultation \\
\hline \multicolumn{2}{|l|}{ Policy } \\
\hline Study population & Local, state, and national policymakers; policy and project implementers \\
\hline Data collection & IDI \\
\hline Sampling & Purposive for IDI \\
\hline
\end{tabular}

Abbreviations: FGD = focus group discussion; IDI = in-depth interview; $\mathrm{NGO}=$ nongovernmental organization. 
Table 2. Study Groups and Data Collection Methods, 2007-2008

\begin{tabular}{|c|c|}
\hline Study Group & Data Collection Method \\
\hline \multicolumn{2}{|l|}{ Individual } \\
\hline Adolescent girls & 26 FGDs 2 IDIs (peer educators) \\
\hline \multicolumn{2}{|l|}{ Interpersonal } \\
\hline Parents/guardians of 10- to 14-year-old girls & 42 FGDs $($ Mothers $=22$, Fathers $=20) 4$ IDIs $($ Mothers $=3$, Fathers $=1)$ \\
\hline \multicolumn{2}{|l|}{ Community/Civil society } \\
\hline Community leaders & 11 IDIs \\
\hline Opinion (religious) leaders & 5 IDIs \\
\hline Local NGO representatives & 4 IDIs \\
\hline \multicolumn{2}{|l|}{ Institutional: Education sector } \\
\hline Teachers & 17 FGDs \\
\hline Head teachers & 3 IDIs \\
\hline \multicolumn{2}{|l|}{ Institutional: Health sector } \\
\hline Health workers & 10 FGDs \\
\hline Health administrators & 18 IDIs \\
\hline Health facilities & 10 facility assessments \\
\hline Vaccination sessions & 11 vaccination session observations \\
\hline Immunization users & 45 exit interviews \\
\hline Immunization experts & 3 consultations \\
\hline \multicolumn{2}{|l|}{ Policy sector } \\
\hline Policymakers & 12 IDIs \\
\hline Policy-influencers & 9 IDIs \\
\hline
\end{tabular}

Abbreviations: $\mathrm{FGD}$ = focus group discussion; IDI = in-depth interview; $\mathrm{NGO}$ = nongovernmental organizations.

current immunization delivery structures, previous vaccine campaigns, and concerns about the HPV vaccine (Table 3). The themes investigated during interviews with policymakers and policy-influencers were developing HPV vaccine policies, policy prioritization process, policy formulation and implementation, and negotiation for implementation of HPV vaccine policy (Table 3 ).

\section{Analysis of Data}

We developed analysis codebooks based on themes, subthemes, and research queries that were pre-defined to match our key research objectives, the research areas of inquiry, as well as those that emerged from the data. Teams synthesized and further analyzed textual data using a group-based iterative process, combining inductive and deductive processes and using several cross-mapping exercises [19]. Where possible, we synthesized findings by state, by rural-urban or tribal settings, and by study groups.

The guidelines for the focus group discussion (verbal informed consent and $\operatorname{logs}$ ) and face-to-face interview tools (written consent forms) were developed in English and translated into Telugu and Gujarati, the local languages. Informed consent was given before group discussions and interviews were conducted.

The formative study protocol was reviewed and approved by NARI's Ethics Committee. Approvals from the Andhra Pradesh and Gujarat Health Ministries were also obtained before starting the data collection field work. All research guidelines, verbal consent forms, and $\operatorname{logs}$ for focus group discussions, as well as written consent for face-to-face interviews, were approved by the Ethics Committee.

\section{RESULTS}

Table 2 provides a summary of completed data collection activities in Khammam by study group and ecological level. This table also highlights the success of researchers' efforts to include the targeted audiences in this study. A total of 223 adolescent girls (141 in Andhra Pradesh and 82 in Gujarat) participated in 26 focus group discussions. Tables $\mathbf{4 a}$ and $\mathbf{4 b}$ 
Table 3. Thematic Areas Explored

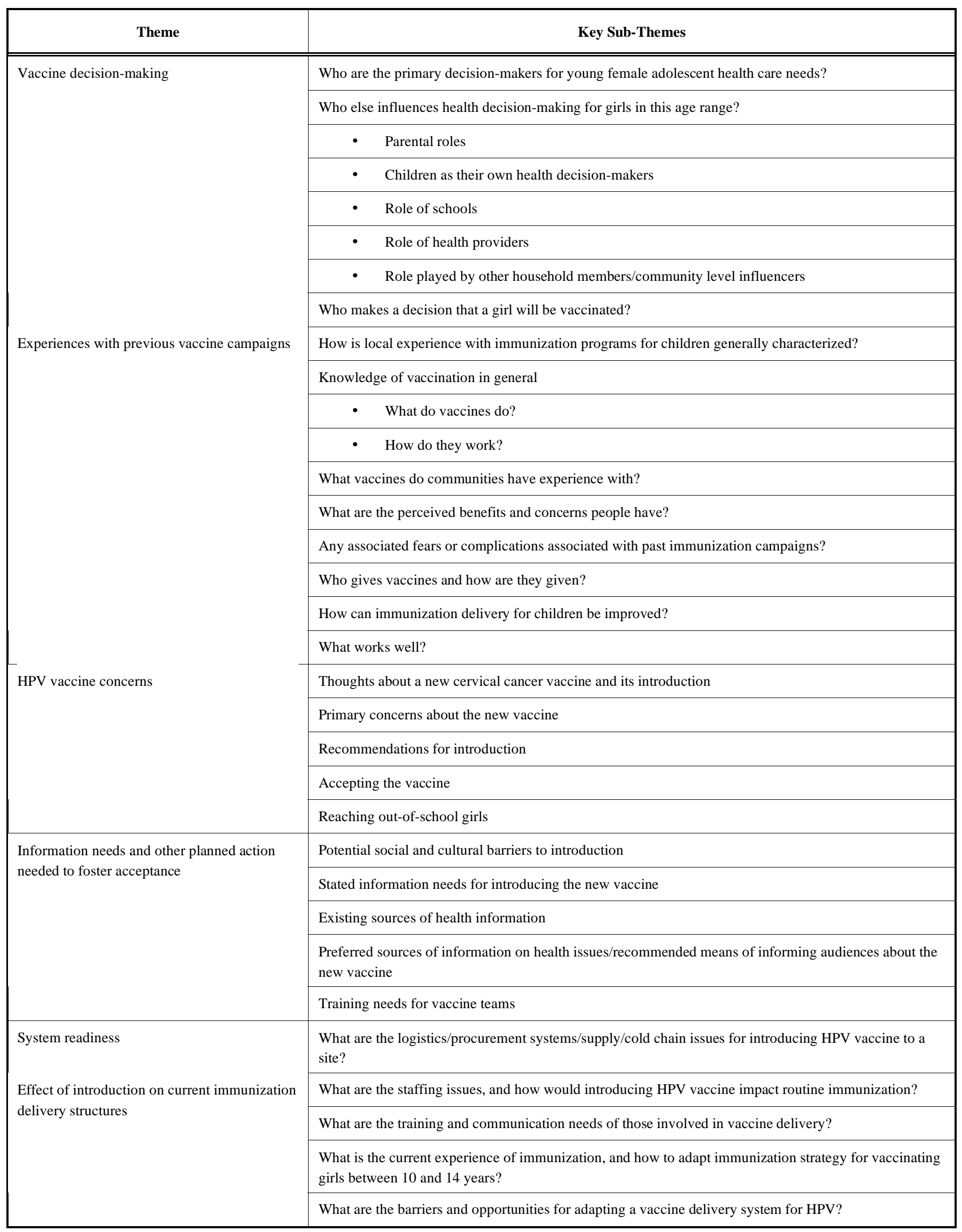


Table. 3. contd....

\begin{tabular}{|c|c|}
\hline Theme & Key Sub-Themes \\
\hline Developing HPV vaccine policies & How is immunization policy developed and decided, who is involved, and what is the process? \\
\hline Policy prioritization process & $\begin{array}{l}\text { What is the level of understanding among policymakers around cervical cancer disease burden, risks, } \\
\text { causes and prevention methods? }\end{array}$ \\
\hline Policy formulation and implementation & When and how HPV vaccine might fit within adolescent health policy and agenda \\
\hline $\begin{array}{l}\text { Negotiation for implementation of HPV } \\
\text { vaccine policy }\end{array}$ & What are some of the key leverages and landmines from a policy standpoint? \\
\hline
\end{tabular}

provide age and educational background information on key adult study participants who are considered primary and secondary influencers on adolescent girls. Among samples drawn in both states, overall, mothers had the highest illiteracy rates, while teachers generally have higher levels of education than either parent. Fathers in the Gujarat sample had higher overall education levels than mothers or fathers in Andhra Pradesh.

\section{Sociocultural Environment}

\section{Concept of Health and Health-Seeking Behavior}

In general, respondents noted essential factors for good adolescent health included nutritious food, clean water, exercise, personal hygiene, health awareness, and vaccination. According to Andhra Pradesh teachers, menstruation is a primary reason for absenteeism and drop-out from schools, and issues related to menstruation were frequently expressed as health concerns for adolescent girls. In Gujarat, on the other hand, adolescent girls' specific concerns included adaptation to bodily changes, onset of menstruation, development of body hair, and anemia.

\section{Decision-Makers for Adolescent Girls' Health}

In all settings, decisions related to an adolescent daughter's health were generally viewed as a joint effort. Teachers in rural sites viewed both the father and mother as being important decision-makers.

However, there were nuances that this generalized perception masked. One of them was revealed in this quote from a focus group of rural mothers:

The mothers would be the decision-makers on their daughters' health but with prior permission from the fathers.

Table 4a. Age and Education Status of Adult Study Participants, Khammam, Andhra Pradesh

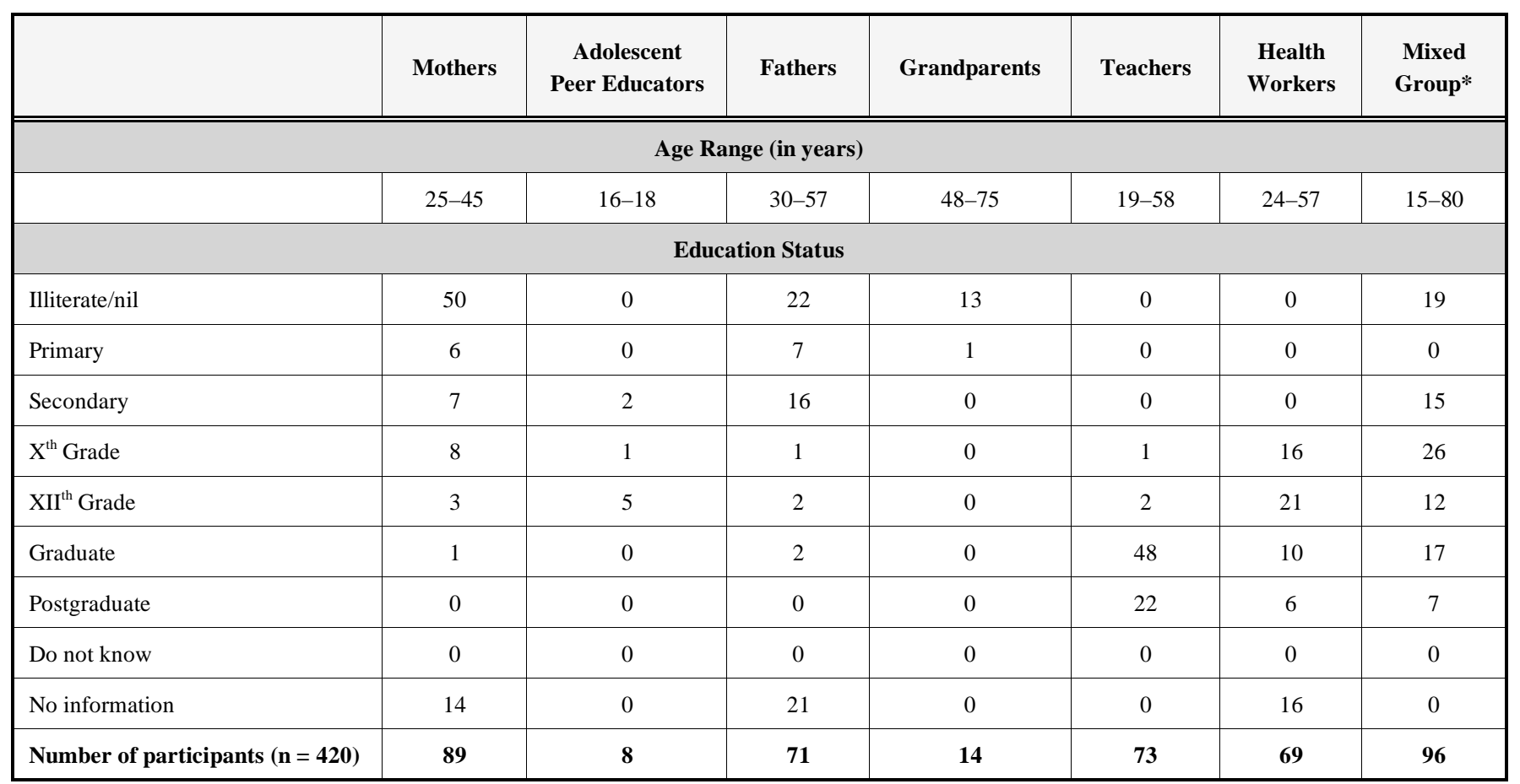

* Mixed Group: Unlike the other focus groups in the study, mixed groups were heterogeneous, and their composition varied from one mixed group to another. These mixed groups usually comprised of community health workers (anganwadi workers or anganwadi helpers), village leaders, Development of Women and Children in Rural Areas members, women's group members, headmasters, Registered Medical Practitioners, and religious leaders. Occasionally, teachers who had not participated in teachers' focus groups and adolescent girls (kishore ballikas) also participated in some mixed groups. 
Table 4b. Age and Education Status of Adult Study Participants, Vadodara, Gujarat

\begin{tabular}{|c|c|c|c|c|c|}
\hline \multicolumn{6}{|c|}{ Age Range (in years) } \\
\hline \multicolumn{6}{|c|}{ Education Status } \\
\hline Primary & 11 & 7 & 0 & 0 & 14 \\
\hline Secondary & 16 & 16 & 0 & 0 & 0 \\
\hline$X^{\text {th }}$ Grade & 9 & 17 & 19 & 9 & 24 \\
\hline XII ${ }^{\text {th }}$ Grade & 3 & 4 & 5 & 9 & 10 \\
\hline Do not know & 0 & 0 & 0 & 0 & 0 \\
\hline Missing information & 4 & 0 & 0 & 7 & 7 \\
\hline Number of participants $(n=325)$ & 79 & 78 & 61 & 29 & 78 \\
\hline
\end{tabular}

* Mixed Group: Unlike the other focus groups in the study, mixed groups were heterogeneous, and their composition varied from one mixed group to another. These mixed groups usually comprised of community health workers (anganwadi workers or anganwadi helpers), village leaders, Development of Women and Children in Rural Areas members, women's group members, headmasters, Registered Medical Practitioners, and religious leaders. Occasionally, teachers who had not participated in teachers' focus groups and adolescent girls (kishore ballikas) also participated in some mixed groups.

Closer analysis of the narrative texts showed decisionmaking power lay with the economic provider of the family, as illustrated below:

The decision-maker obviously would be the father... because of [the] economic link. And he decides... where to go and what to do.

\section{- Grandmothers' group, rural}

Participants in all groups agreed that mothers were key caregivers for adolescent girls and generally made decisions related to their daughters' health. Fathers intervened if matters turned serious or if there was a major financial implication, such as would be the case with vaccination. Thus, decision-making was not a unilateral process, but rather occurred in the context of multiple social relationships.

\section{Decision-Influencers}

Beyond the parents, other important entities appeared to have some influence in health decision-making for girls. Respondents in Khammam suggested members of the NGO Janani, peer educators, female teachers, and relatives would be other key influences. Government as well as mandal officers were also an important influence. In remote tribal areas, health volunteers also would play a key role. Grandmothers in Andhra Pradesh as well as aunts (kakis) and sisters-in-law (bhabhis) in Gujarat were reported as influences within the extended family.

Under the framework of the National Rural Health Mission, committees were established in all villages to monitor implementation of health-related activities. These committees employ the efforts of a gram mitra (an individual ap- pointed as the village's resource person), nurse, and sarpanch (elected village head) to help carry out their healthrelated mission. Through their community engagement, these individuals also play a role in influencing vaccination decision-making. Respondents suggested these committees as potential avenues for project activities.

\section{Understanding and Perception of Cancer, Cervical Cancer, and its Implications}

There was awareness among community members about cancer in general, but limited awareness of cervical cancer. Cervical cancer, referred to as "garbhasanchi cancer" in Andhra Pradesh and "garbhashay cancer" in Gujarat, is roughly translated in popular perception as "cancer of the womb." Respondents did not distinguish between womb cancer and cervical cancer, and felt that "garbhasanchilgarbhashay" cancer was common among women over 40 years of age.

In Andhra Pradesh, the psychological, social, and financial impacts of the disease on individuals and households were specifically mentioned. In Gujarat, social factors such as stigma were emphasized. For example, a woman with cervical cancer could face ostracism, and her family could, as well.

Local understanding of the causes of garbhasanchilgarbhashay cancer included poor hygiene, a risk-prone sexual history (e.g., multiple sex partners, unsafe sex, and sexually transmitted infections), and pregnancy-related issues (e.g., multiple deliveries, abortions, and menstrual disorders). A majority of respondents were unaware that cervical cancer was preventable and had not heard of a vaccine or pre-cancer screening and treatment. 
Indeed, there was a sense of fatalism. In Andhra Pradesh, most respondents felt "Cancer ante cancel (Cancer means cancel/it's over)"; the corresponding phrase in Gujarat was "Cancer etle manas cancel (Cancer means a human life is cancelled/death)."

\section{Experiences with Vaccination}

By and large, respondents had positive attitudes toward vaccination as a preventive tool. For the most part, prevention was seen as better than cure. There was trust in the national immunization program vaccines, which are easily accessible and administered through government health facilities at no cost. Childhood immunizations such as the oral polio vaccine, the Japanese encephalitis vaccine, and the tetanus toxoid vaccine were well-known. Most parents also felt vaccination programs were well-implemented in their village.

Some community-level participants felt adolescent vaccines would be redundant if a child had received the entire course of vaccines administered during infancy and childhood.

After the child crosses five years, no parent shows interest in any of the vaccines. At least most of the parents behave in this manner.

- Teachers' group, urban

\section{Thoughts About Cervical Cancer Vaccine and its Introduc- tion}

Vaccine cost was a concern. There was widespread belief that vaccines delivered by the government health system were affordable. Some respondents said they would prefer free access to the vaccines, but they were willing to pay a small amount depending on income levels. Definitions of what constituted an affordable price varied from Rs 10 to Rs 150 (US\$0.20 to US\$3.30). The most common range was between Rs 25 and Rs 30 (US\$0.50 to US\$0.65). In Gujarat, opinions differed between adolescent girls and other study groups. Here, some adolescent girls feared free vaccines might be of poor quality.

There were concerns relating to HPV vaccine side effects expressed by both community members and health care providers. Across religious lines, Hindu, Muslim, and Christian respondents said there would be no faith-based obstacles if the vaccine was found to be beneficial for girls. However, there were some apprehensions about its impact on a girl's fertility and child-bearing ability.

\section{Suggested Communication Messages and Experience with Communication on Health Matters}

Respondents among health care providers felt target audiences-adolescent girls and those who made or influenced decisions related to their health (e.g., parents, teachers, and peer educators) - would need to receive and internalize the following set of key messages:

(i) Cervical cancer is a leading cancer affecting women;

(ii) There are ways to prevent it;

(iii) The HPV vaccine is one of them.

In addition, the community needed information about vaccine characteristics and potential side effects.
Suggested national media information sources were television, radio, and print, using celebrity spokespersons. Suggested local media information sources were radio, group meetings, street plays, local cultural artists, and one-on-one communication with trained community health workers and peer educators. Endorsements of the vaccine by the government, celebrities, mass media, and community leaders were considered essential.

\section{Health Systems \\ Existing Health Services and Schemes}

The two Indian states studied had been implementing programs under the National Rural Health Mission. Vaccination programs, such as that for tetanus toxoid booster shots, were being implemented by the State Health Services. The Integrated Child Development Services scheme was being rolled out by the Department of Women and Child Development. The Education Department's Sarva Shiksha Abhiyan (a mission to establish universal elementary education) also had a health component.

In Andhra Pradesh, hepatitis B vaccination was part of the universal immunization program. In Gujarat, the hepatitis $B$ vaccine was provided in a few urban areas through the public health system. In Gujarat, health services were provided through effective public-private partnerships such as the Chiranjeevi Yojana and the Rajiv Gandhi Urban Health Mission. In Andhra Pradesh, the Rajiv Aarogyasri Community Health Insurance Scheme had been implemented for families living below the poverty line. This could be relevant for HPV vaccine introduction, given the insurance scheme aims at improving access to cancer treatment. There is potential for expansion of the scheme to include improving access to cancer prevention methods, such as HPV vaccination, to reduce treatment costs.

\section{Current Status of Immunization Services}

\section{Vaccine Storage System}

At the state and district levels, vaccines were stored in walk-in coolers. At district, block, and primary health center (PHC) levels, vaccines were stored in ice-lined refrigerators. We found additional cold storage space available in the study districts and at the regional and state levels. The existing vaccine storage space, distribution process, and reporting system were robust and adequate for the introduction of the HPV vaccine (Table 5).

\section{Immunization Sessions}

For all observed sessions, including outreach, vaccines and ice packs were received on session day from vaccine storage at the PHCs. Care was taken while transferring the vaccines from storage to distribution and vaccination sites. A record-keeping system for distributed vaccines was found to be in place, but the system would benefit from strengthening. ANMs, male health workers, and anganwadi (village health center) workers (AWWs) were responsible for mobilizing and vaccinating children. The number of ANM vacancies in Gujarat was an issue raised by service providers.

\section{Injection Safety}

Government of India guidelines on injection safety were implemented at the field level. Safe injection disposal sys- 
Table 5. Total available cold space in Andhra Pradesh and Gujarat

\begin{tabular}{|l|c|c|c|c|c|c|}
\hline & \multicolumn{3}{|c|}{ Andhra Pradesh } & & Gujarat \\
\cline { 2 - 7 } & Existing Space & Utilized For UIP & Available Space & Existing Space & Utilized For UIP & Available Space \\
\hline \hline State level & 33,000 & 20,790 & 12,210 & 16,500 & 15,544 & 956 \\
\hline Regional level & 16,500 & 2,543 & 13,957 & 16,500 & 2,789 & 13,711 \\
\hline District level & 1,213 & 235 & 978 & 564 & 235 & 329 \\
\hline
\end{tabular}

Note: Above figures are in liters.

Abbreviations: UIP $=$ universal immunization program.

tems were in place, with some inter-state variability in implementation. In Andhra Pradesh, syringes were kept in puncture-proof containers at outreach session sites.

\section{Reporting Systems}

A combination of electronic and manual reporting systems and the Routine Immunization Monitoring System (RIMS) software, recommended by the Government of India, were in use in both states. Though immunizationrelated activities data gathering and reporting were similar in both states, the nomenclature for the reporting forms differed.

Adverse events following immunization (AEFI) management: Records review showed that AEFI guidelines, although available, were not adhered to. AEFI data was entered in the reporting format in a sporadic manner. Forms were not submitted regularly, nor were there regular reviews.

\section{Suggested Vaccine Delivery Strategies}

The following three broad approaches were suggested by policy implementers, service providers, and NGOs for HPV vaccine delivery:

(i) Merge HPV vaccination with already established immunization services;

(ii) Package HPV immunization with adolescent health services or as a part of a cancer control service;

(iii) Deliver HPV vaccinations through either routine immunization services or a campaign using schools as vaccination sites for school-going girls and anganwadi centers for non-school-going girls.

Additionally, in Andhra Pradesh, a two-step method was suggested. In the first year, HPV vaccines would be administered to a cohort of 10- to 14-year-old girls (grades 5-9). In the second year, HPV vaccines would be administered to a cohort of 10-year-old girls (grade 5). Some health providers and policymakers also recommended a "mother-daughter package." This package approach would entail providing precancer screening and treatment to women aged 30 years or older (secondary prevention) and administering HPV vaccines to adolescent girls (primary prevention).

\section{Factors That Can Affect HPV Vaccine Uptake}

Endorsement by the government, professional associations, and the community were seen as vital for HPV vaccination acceptance. In both states, cost and side effects of the new vaccine, staff vacancies, and additional workload resulting from vaccine introduction were concerns among service providers. Some service providers suggested different pricing for different community strata, with the individual capacity to pay factored in.

During the health systems review, most participants noted that current staffing is inadequate for HPV vaccine delivery. In the view of policymaking respondents, the number of adolescent girls between the ages of 10 and 14 was not large, but the staff had to be willing to provide HPV services in addition to their existing workload. Mid-level supervisory officials felt staff shortage would adversely affect work quality, but the ANMs felt work schedules would not be affected if tasks were shared among them.

Immunization experts in Gujarat, while focusing on policymaking issues in the consultation workshops, felt the vaccine should be initially introduced in the private sector to test its acceptability since administration by private sector providers implicitly functions as an early indicator of the cumulative demand for the vaccine in the population. This could help minimize the risk of failure in HPV vaccine uptake once the decision is taken to incorporate the vaccine into the public sector and public health programs.

\section{Policy Environment}

\section{Understanding of Cervical Cancer and its Implications}

National policymakers and representatives of national and state professional organizations seemed to be knowledgeable about causes of cervical cancer, links between HPV and cervical cancer, cervical cancer prevention, and current prevention efforts in India. However, awareness was limited on the burden of the disease. The general perception was that though cervical cancer was prevalent in India, it was not as much of a problem as in African countries. A majority felt cervical cancer constituted 5 to 15 percent of health issues among women.

\section{Policymaking Process}

According to the respondents, the policy prioritization process would involve collecting information on HPV disease burden, vaccine efficacy and safety studies, and designing mechanisms for management of any adverse events following HPV vaccination. Increasing awareness about cervical cancer would catalyze capacity-building to deal with the burden of the disease. Women's health activists were felt to 
have an important role in placing and keeping this issue on the political agenda.

The key issues for policy players were information on price, vaccine safety and efficacy, interaction with other health programs, alternatives to introducing the vaccine, scientific opinions on the vaccine, surveillance, quality control, and exploration of financing options for introducing the vaccine. Focus should be on a life-cycle approach-infancy, childhood, adolescence, and adulthood. Hence, there would need to be smooth coordination between the Department of Health, Department of Education, and Department of Women and Child Development.

A dominant view was that the HPV vaccine had to be only one element in a comprehensive cervical cancer prevention program. There is no specific niche for this vaccine, as policy guidelines could fall under the cancer, adolescent health, and immunization rubrics.

\section{Concerns and Acceptability among Policymakers and Pol- icy-Influencers}

Vaccine cost and the implications of introducing a new vaccine into the health system were mentioned as crucial issues by policymakers, influencers, and implementers. Managing adverse events following immunization was critical to ensure viability, and many said this could affect acceptance of the vaccine.

According to policymakers, the political leadership's focus on women's health would be a vital element for vaccine acceptance. They also felt building community trust with clear explanations of the purpose of HPV vaccine introduction using key players would help gain acceptance. In Gujarat, setting up public-private partnerships and developing pre-commitment orders to help a community reduce costs were considered key strategies.

\section{DISCUSSION}

This study provided insights on the sociocultural milieu, health system structures, and policy environment for designing HPV vaccine delivery strategies; a communication strategy for community outreach; and an advocacy strategy to access policymakers. The information from the study would be useful not just for demonstration projects, but for any HPV vaccination effort.

The forthcoming India demonstration project will test the three outputs to evaluate their effectiveness (coverage), feasibility, cultural appropriateness (acceptability), and cost. It will also determine the best approaches. The evidence generated will specify the human, operational, and financial inputs necessary to add the HPV vaccine to other existing or planned health promotion activities.

The approach currently followed for wide-scale new vaccine introduction has been prescriptive and largely focused on the biomedical aspects of disease and vaccines [12, 20]. This traditional approach often falls short in building acceptance among potential providers and recipients by failing to address vaccination in the socio-cultural context of their daily lives. Our formative study focused on a different, more holistic approach to vaccine introduction, coupled with education and counseling, that took into account the beliefs, cultures, and practices of the communities studied.
Nevertheless, issues stemming from this approach at a deeper systemic level, as well as those of actual community and provider acceptance, would be revealed only after direct experience in implementing HPV vaccination in the Indian sociocultural context. A range of issues was explored based on the research queries and sampling criteria outlined in previous sections. However, the study did not conduct separate focus group discussions to explore possible differences in the views of specific castes, communities, economic classes, and religions. The findings also may not be generalized to apply to the rest of the country.

\section{HPV Vaccine Delivery Strategies to Reach Adolescent Girls}

An overwhelming number of participants, community representatives, service providers, and policymakers stressed HPV vaccine should be delivered using existing immunization services. Service providers recommended the HPV vaccine be introduced in a two-step approach as part of India's current immunization program, either through routine monthly services or a special campaign similar to the polio vaccination program.

Health systems in the study areas did not require large infrastructure investments to introduce the HPV vaccine. The basic cold chain and logistic equipment were available. However, new vaccines would need to be tested in small demonstration projects to determine the best strategy for wider use in India. Injection safety, reporting and monitoring of AEFI, and implementation of RIMS would also need to be strengthened if the HPV vaccine was added to existing services.

This in turn would open doors for strengthening existing immunization structures through training and supportive supervision, which would need to be strengthened for sustainability.

Other crucial learning opportunities presented by a small demonstration project would be ensuring and sustaining coordination among state and district authorities as well as among the Department of Health, Department of Women and Child Development, and Department of Education. However, care would be needed to maintain HPV vaccination among the priorities of the immunization system and the adolescent health program.

\section{Community Perspectives and their Implications for Vaccine Acceptance and Delivery}

In terms of developing community messages about HPV vaccination, the guiding principle that emerged from the formative study was that message content should address concerns raised by the communities [21]. Messages need to provide information on how to prevent the disease, vaccine safety, vaccine efficacy, and the vaccine's effect on future fertility.

It was important to use a holistic approach by placing this information in the framework of immediate adolescent health education needs. Messages ought to be simple, clear, and consistent. The experience of other vaccination communication strategies was available and could be borrowed from. 
Though study participants were aware of the benefits of vaccines for children, adolescent vaccination for cervical cancer prevention was a fairly new concept. This finding is helpful for developing and disseminating information addressing the currently low knowledge level about cervical cancer, HPV, and HPV vaccination.

The groups to reach through communication efforts would be key family members and community health issues' decision-makers and influencers. Questions and concerns about the vaccine, such as fear of side effects, would need to be addressed. Using both national and local media, as well as direct communication, to educate parents, girls, and potential decision-influencers would be needed.

A crucial element for vaccine acceptance would be involving the community's gatekeepers (e.g., local leaders, health workers, and teachers), whose counsel is sought before important decisions, as the starting point for acceptance and information dissemination. This would involve tailoring cervical cancer prevention messages for this audience. However, we would be working with a clean slate, similar to the starting point found in Uganda [22].

\section{Advocacy Approaches}

Although there was awareness of cervical cancer among policymakers, most felt that it was not among the pressing health issues facing India. A successful advocacy strategy would need to involve getting the issue on the political agenda, as well as providing evidence in support of an effective and feasible health intervention, such as HPV vaccination, that can be implemented through the existing health system.

Policymakers felt it was crucial to build partnerships among stakeholders (policymakers, professional medical bodies, and women's health activists) in order for a cervical cancer prevention program to get political endorsement. Political endorsement would build on the existing positive culture for vaccination at the community level. The partnershipbuilding efforts would benefit from strategies such as a comprehensive cervical cancer prevention model package (comprised of health education, primary, and secondary prevention). HPV vaccination would be one of the elements in this model package.

This finding is in line with the declaration adopted in Mexico City at the Region of the Americas 2008 Pan American Health Organization stakeholders' meeting [23] and with World Health Organization recommendations [24].

There are many challenges to making a comprehensive cervical cancer prevention program a reality in India. The program would need to combine efforts of several government departments, both at the national and state levels, at the implementation, resource allocation, and coordination stages. These would be the Department of Education, various programs within the Department of Health, schemes within the Department of Women and Child Development, and the Department of Panchayati Raj.

In addition to the enormity of designing a crossdepartmental infrastructure, findings of a study in South Africa point to the need for including yet another department in that country's structure, the Department of Sexual and
Reproductive Health. Cervical cancer, after all, is seen as a sexual and reproductive health issue [25].

\section{CONCLUSION}

In summary, effective health program planning is necessary to structure and address the needs and concerns about the new vaccine as expressed by different stakeholders. It also has to be applicable to local contexts.

This formative study data has helped unravel the complex and co-dependent factors surrounding vaccination and cervical cancer prevention. It has thereby assisted in laying the groundwork for planning and preparing HPV vaccination strategies that would be assessed before large-scale implementation. The findings could help build a comprehensive cervical cancer prevention program within which the HPV vaccine would be embedded, should the Government of India move forward with plans to introduce the vaccine.

\section{ACKNOWLEDGEMENTS}

We extend gratitude to our field investigators in both Andhra Pradesh and Gujarat for their hard work and commitment. We are indebted to all the study participants, without whom this study would not have been possible. The guidance provided by the ICMR-PATH Project Advisory Group and the Gujarat and Andhra Pradesh State Advisory Groups chaired by the respective commissioners of family welfare, was critical. Thanks, too, to Vivien Tsu, Scott Wittet, and our Expert Reviewers for their invaluable input throughout the study. Generous funding for this work was provided through a grant to PATH from the Bill \& Melinda Gates Foundation.

\section{REFERENCES}

[1] Ferlay, J.; Bray, F.; Pisani, P.; Parkin, D.M. GLOBOCAN: Cancer Incidence, Mortality, and Prevalence Worldwide, IARC CancerBase No. 5, version 2.0. 2002. http://www-dep.iarc.fr/globocan/ database.htm (accessed May 16, 2008).

[2] National Cancer Registry Programme (NCRP), Indian Council of Medical Research (ICMR). Incidence and Distribution of Cancer: Consolidated Report of Population Based Cancer Registries, 20012004; NCRP, ICMR: Bangalore, 2006. Available from: http:// www.icmr.nic.in/ncrp/report_pop_2001-04/cancer_p_based.htm.

[3] NCRP, ICMR. An Assessment of the Burden and Care of Cancer Patients: Consolidated Report of Hospital Based Cancer Registries, 2001-2003; NCRP, ICMR: Bangalore, 2007. Available from: http://www.icmr.nic.in/ncrp/report_pop_hos_2001-03/cancer_h_based. htm.

[4] Bhatla, N.; Dar, L.; Patro, A. R.; Kriplani, A.; Gulati, A.; Verma, K.; Broor, S.; Shah, K.V.; Gravitt, P.E. Human papillomavirus type distribution in cervical cancer in Delhi, India. Int. J. Gynecol. Pathol., 2006, 25 (4), 398-402.

[5] Sowjanya, A.P.; Jain, M.; Poli, U.R.; Padma, S.; Das, M.; Shah, K.V.; Rao B.N.; Devi R.R.; Gravitt, P.E.; Ramakrishna G. Prevalence and distribution of high risk papilloma virus (HPV) types in invasive squamous cell carcinoma of the cervix and in normal women in Andhra Pradesh, India. BMC Infect. Dis., 2005, 5, 116.

[6] Sankaranarayanan, R.; Esmy, P.O.; Rajkumar, R.; Muwonge, R.; Swaminathan, R.; Shanthakumari, S.; Fayette J.M., Cherian J. Effect of visual screening on cervical cancer incidence and mortality in Tamil Nadu, India: a cluster-randomized trial. Lancet, 2007, 370 (9585), 398-406.

[7] Denny, L.; Kuhn, L.; De Souza, M.; Pollack, A.E.; Dupree, W.; Wright, T.C. Jr. Screen-and-treat approaches for cervical cancer prevention in low-resource settings: randomized controlled trial. JAMA, 2005, 294 (17), 2173-2181. 
[8] Sankaranarayanan, R.; Gaffikin, L.; Jacob, M.; Sellors, J.; Robles, S. A critical assessment of screening methods for cervical neoplasia. Int. J. Gynaecol. Obstet., 2005, 89 (Suppl 2), S4-S12.

[9] Jacob, M.; Broekhuizen, F.F.; Castro, W.; Sellors, J. Experience using cryotherapy for treatment of cervical precancerous lesions in low-resource settings. Int. J. Gynaecol. Obstet, 2005, 89 (Suppl 2), S13-S20.

[10] World Health Organization (WHO). Human papillomavirus vaccines: WHO position paper. Wkly. Epidemiol. Rec., 2009, 84 (15), 118-131.

[11] Guest, G.; MacQueen, K. M., Eds.; Handbook for Team-Based Qualitative Research; Altamira: Lanham, 2008.

[12] Bingham, A.; Janmohamed, A.; Bartolini, R.; Creed-Kanashiro, H.; Katahoire, A.; Khan, I.; Lyazi, I.; Menezes, L.; Murokara, D.; Nguyen, N.; Tsu, V. An approach to formative research in HPV vaccine introduction planning in low-resource settings. Open Vaccine J., 2009, 2, 1-16.

[13] Breinbauer, C.; Maddaleno, M. Youth: Choices and Change. Promoting Health Behaviors in Adolescents. Pan American Health Organization: Washington, DC, 2005.

[14] Sherris, J.; Friedman, A.; Wittet, S.; Davies, P.; Steben, M.; Saraiya, M. Chapter 25: Education, training, and communication for HPV vaccines. Vaccine, 2006, 24 (Suppl 3), S210-S218.

[15] International Institute for Population Sciences (IIPS) and Macro International. National Family Health Survey (NFHS-3), 2005-06: India; IIPS: Mumbai, 2007. Available from: http://www.nfhsindia. org/nfhs3_national_report.html.

[16] IIPS. District Level Household Survey (DLHS-2), 2002-04: India; IIPS: Mumbai, 2006. Available from: http://www.mohfw.nic.in/ dlhs_2002.htm.

[17] Registrar General and Census Commissioner of India. Census of India, 2001. http://www.censusindia.gov.in (accessed May 20, 2008).
[18] District Information System for Primary Education (DISE). District Report Cards, Raw Data 2004-2005. http://www.dise.in (accessed May 20, 2008).

[19] Miles, M.B.; Huberman, A.M. Qualitative Data Analysis: An Expanded Sourcebook; Sage Publications, Inc.: Thousand Oaks, 1994.

[20] Jheeta, M.; Newell, J. Childhood vaccination in Africa and Asia: the effects of parents' knowledge and attitudes. Bull. World Health Organ., 2008, 86 (6), 419-420.

[21] Bingham, A.; Drake, J.K.; LaMontagne, D.S. Sociocultural issues in the introduction of human papillomavirus vaccine in lowresource settings. Arch. Pediatr. Adolesc. Med., 2009, 163 (5), 455461.

[22] Katahoire, R.A.; Jitta, J.; Kivumbi, G.; Murokora, D.; Arube, W.J.; Siu, G.; Arinaitwe, L.; Bingham, A.; Mugisha, E.; Tsu, V.; LaMontagne, D.S. An assessment of the readiness for introduction of the HPV vaccine in Uganda. Afr. J. Reprod. Health, 2008, 12 (3), 159-172.

[23] Pan American Health Organization Mexico City declaration by participants to the meeting for comprehensive cervical cancer prevention and control. Immunization \& protect your family. Immunization Newsletter, 2008, XXX (4), 8. Available from: http:// www.paho.org/English/AD/FCH/IM/Sne3004.pdf

[24] WHO; United Nations Population Fund (UNFPA). Preparing for the Introduction of HPV Vaccines: Policy and Program Guidance for Countries, (WHO/RHR/06.11), WHO: Geneva, 2006. Available: http://whqlibdoc.who.int/hq/2006/WHO_RHR_06.11_ eng.pdf

[25] Harries, J.; Moodley, J., Barone, M.A.; Mall, S.; Sinanovic, E. Preparing for HPV vaccination in South Africa: key challenges and opinions. Vaccine, 2009, 27 (1), 38-44. 